\title{
RED CELL DISTRIBUTION WIDTH, NEUTROPHIL LYMPHOCYTE AND PLATELET LYMPHOCYTE RATIOS AS PROGNOSTIC MARKERS IN ACUTELY PESTICIDES- POISONED PATIENTS
}

\author{
Naema Mahmoud Elhosary ${ }^{a, *}$ and Enaam Salah Abd-ElBar ${ }^{b}$ \\ ${ }^{\mathrm{a}}$ Forensic Medicine and Clinical Toxicology and ${ }^{\mathbf{b}}$ Clinical Pathology Departments, Faculty of \\ Medicine, Tanta University, Tanta, Egypt. \\ *Corresponding author: Naema Mahmoud Elhosary, Tanta, Egypt \\ E-mail: dr_naema55@yahoo.com, Mobile: 00201005589216
}

\section{ABSTRACT}

Egypt like other developing countries use pesticides widely to increase crops production and prevent spread of vector-borne diseases. However, pesticides poisoning is considered as a public health problem as it is associated with high morbidity and mortality. Objectives: evaluation the red cell distribution width (RDW), neutrophil lymphocyte ratio (NLR) and platelet lymphocyte ratio (PLR) as prognostic markers in acutely pesticide-poisoned patients. Methodology: eighty patients with acute pesticide poisoning who admitted to Toxicology Unit of Emergency Hospital, Tanta University, were classified into three groups according to their outcome. Three $\mathrm{mL}$ of venous blood were drawn for performing complete blood count (CBC), and were analyzed by hematology analyzer machine. The RDW, NLR, and PLR were assessed. Results: Patients of group (3) had the significant highest total WBCs, neutrophils and platelets counts $(\mathrm{P}<0.001)$. Significant lymphopenia was found in patients of group (3). Moreover, group (3) had

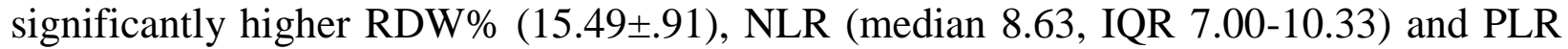
$(362.51 \pm 59.45)$ than groups $1 \& 2(\mathrm{P}<0.001)$. ROC curves showed cut off values of RDW\% $\geq 14.3$ (sensitivity $93.8 \%$ and specificity $83.3 \%$ ), NLR $\geq 6.49$ (sensitivity $87.5 \%$ and specificity 95.8\%), and PLR $\geq 292.87$ (sensitivity $87.5 \%$ and specificity $91.7 \%$ ). These parameters were significantly related to the patients outcome $(\mathrm{p}<0.001)$. Plasma cholinesterase enzyme activity was correlated significantly and negatively with RDW\%, NLR and PLR $(\mathrm{P}<0.001)$. Conclusion: Measured RDW\%, NLR, and PLR are useful, valuable, inexpensive and easily accessible parameters in estimating prognosis and the follow-up of patients with acute pesticides poisoning.

KEYWORDS: Acute pesticide poisoning, Red cell distribution width, Neutrophil lymphocyte ratio, Platelet lymphocyte ratio, Prognosis

\section{INTRODUCTION}

Pesticides are potentially toxic chemical compounds that are mainly used to protect the agricultural crops (Mansour, 2004). Pesticides are +classified into herbicide, insecticide, fungicide and fumigant (Georgiadisa et al., 2018). Among the insecticides; organophosphates, carbamates, organochlorines, and pyrethroids are accounted for human poisoning (Page et al., 2017).

Acute pesticide poisoning leads to great morbidity and mortality, particularly in developing countries as they are commonly used to increase crops production to meet the foods need of the people and their sales are not governed 
(Bertolote et al., 2006). The manner of pesticides poisoning varies between intentional and unintentional. Annually, about 350,000- 440,000 suicidal cases occur throughout the world that result in approximately $250,000-300,000$ deaths, and the number of victims of nonfatal pesticide poisoning are assumed to be much greater (Gunnell et al., 2007 and Cha et al., 2014).

The recognition of potent prognostic biomarkers are needed during the clinical management of acutely pesticide poisoned- patients to predict the outcome. Meanwhile, the clinical significance of the $\mathrm{CBC}$ test in the diagnosis of humans poisoning was examined in few studies (Tang et al., 2018). As CBC is accessible to clinicians as a part of routine investigations.

The red cell distribution width (RDW) is one of the full blood count findings, which determines the size or volume variability of the erythrocytes. The RDW reflects anisocytosis that indicates heterogonous erythrocyte size (Jo et al., 2013). Recently, many studies demonstrated that a high RDW is strongly affiliated with cardiac, hepatic, metabolic patients indicating that RDW represents the inflammatory status of the body (Dabbah et al., 2010; Kim et al., 2012; Zorlu et al., 2012 and Hu et al., 2013).

The neutrophil-lymphocyte ratio (NLR) and the platelet-lymphocyte ratio (PLR) are sensitive inflammatory and independent prognostic markers in many clinical states as sepsis, cardiac disorders, stroke, and acute appendicitis (Zahorec, 2001; Balta et al., 2013; Kaya et al., 2014 and Alan et al., 2015).
The aim of this study was to evaluate the prognostic role of the RDW, NLR and PLR in patients with acute pesticide poisoning.

\section{MATERIALS AND METHODS}

This study was hospital based prospective study. Patients with acute pesticide poisoning admitted to Toxicology Unit of Emergency Hospital of Tanta University, Tanta, Egypt, from May to October 2014 were enrolled in this study. The diagnosis of acute pesticide poisoning was grounded on the history of exposure to a pesticide, the presence of typical clinical manifestations that were improved after supportive and specific treatment.

Exclusion criteria were patients with (i) history of pregnancy, cancer, hematological, cardiovascular, renal, hepatic diseases, diabetes mellitus, trauma, and symptomatic bacterial or viral infection (ii) delay of hospitalization for more than 24 hours after pesticide exposure (iii) administration of any intravenous drugs or undergone any invasive treatment such as hemoperfusion. As all these disorders are accompanied with elevated either RDW or NLR and PLR (Shehata et al., 1998; Li et al., 2017; Tang et al., 2018).

All studied patients underwent thorough history taking which included age, sex, marital status, residence, education, route, manner of pesticide exposure, type and amount of pesticide, time delay of hospital arrival and history of any acute or chronic diseases. Physical examination comprising vital signs (heart rate, blood pressure, respiratory rate, and temperature), head \& neck, chest, and 
abdomen were performed. The level of consciousness was evaluated using the Glasgow Coma scale (GCS).

Five $\mathrm{mL}$ of venous blood were drawn to do routine laboratory investigations and pseudocholinesterase activity.

Regarding the complete blood count (CBC), $3 \mathrm{~mL}$ of venous blood was taken under complete aseptic conditions into heparin lithium-anticoagulant tubes on admission and before administration of any drug medications. This sample was analyzed by hematology analyzer machine (Beckman Coulter, Brea, CA). The RDW was directly obtained by the hematology analyzer. NLR was estimated as absolute neutrophil count divided by absolute lymphocyte number, while PLR was calculated by dividing total platelet number by absolute lymphocyte count.

Outcome of the poisoned patients was studied as regards clinical improvement with or without occurrence of complications or death. They categorized into three groups: group (1); complete recovery, Group (2); complicated recovery and group (3); death. The complications vary according to the causative pesticide agent. Organophosphates and carbamates poisoning is complicated by cardiac arrhythmias, non-cardiogenic pulmonary edema, respiratory depression, aspiration pneumonia, and metabolic acidosis (Faiz et al., 2011). Phosphides toxicity is complicated by hemorrhage, acute renal failure, disseminated intravascular coagulation and arrhythmias (Mehrpour et al., 2012). Pyrethroid poisoning is complicated by respiratory failure, hypotension, acidosis, seizures, and renal failure (Kim et al., 2015). This study was approved by the Ethical Committee of The Faculty of Medicine, Tanta University, Egypt. All included patients or their relatives signed an informed written consent regarding the analysis of their medical data after declaring the objectives and research plan. All patients' information was securely coded and analyzed.

\section{STATISTICAL ANALYSIS}

For quantitative data, the Shapiro-Wilk test for normality was performed. For data that were not normally distributed, median and interquartile range (expressed as $25^{\text {th }}-75^{\text {th }}$ percentiles) were calculated and Kruskal-Wallis test was used for comparison between groups. For normally distributed data, values were expressed as mean \pm standard deviation and one-way ANOVA test was performed for comparison between groups. When results of these tests were significant, the suitable posthoc tests were done for pairwise comparison. For qualitative data, they were expressed as numbers and percentages in brackets. In addition, Spearman's rank correlation was done to test association of cholinesterase level and the studied hematological parameters. For prediction of the prognosis of the studied patients by using RDW\%, NLR, and PLR, Receiver Operating Characteristic (ROC) curves were constructed. Significance was adopted at $\mathrm{p}<0.05$ for interpretation of results of tests. All analyses were done using SPSS version 20 (Knapp, 2017)

\section{RESULTS}

This study was carried on eighty patients aged between 18 and 60 years who were poisoned with different types of pesticides. All patients arrived at the toxicological unit within 1-13 hours 
post-exposure to pesticides (Median 3.0, IQR 2.0-6.0 hours) and stayed in hospital for a mean duration of 5.3 \pm 3.2 days. The mean systolic blood pressure was $108.50 \pm 22.37 \mathrm{mmHg}$ while, the median diastolic blood pressure was 70.00 (IQR 50.00-80.00) $\mathrm{mmHg}$.

Most of the enrolled patients were married male farmers as presented in Table1.

Table (1): Demographic data and general characteristics of the studied patients

\begin{tabular}{|c|c|c|c|}
\hline \multicolumn{2}{|c|}{ Character } & \multirow{2}{*}{$\begin{array}{c}\mathbf{N}=80 \\
14 \\
\end{array}$} & \multirow{2}{*}{\begin{tabular}{|c|} 
Percentage \% \\
17.5 \\
\end{tabular}} \\
\hline Sex & Female & & \\
\hline & Male & 66 & 82.5 \\
\hline \multirow{2}{*}{$\begin{array}{l}\text { Marital } \\
\text { Status }\end{array}$} & Married & 58 & 72.5 \\
\hline & Single & 22 & 27.5 \\
\hline \multirow[t]{2}{*}{ Residence } & Rural & 58 & 72.5 \\
\hline & Urban & 22 & 27.5 \\
\hline \multirow[t]{3}{*}{ Occupation } & Farmer & 66 & 82.5 \\
\hline & Housewife & 10 & 12.5 \\
\hline & Students & 4 & 5.0 \\
\hline
\end{tabular}

N: Number

The accidental manner of poisoning was the predominant. Higher percentage of patients exposed to the anticholinesterases insecticides including organophosphates and carbamates through mixed routes as inhalation, skin, and or ingestion. The lowest pesticides exposures were pyrethroid and organochlorine $(2.5 \%)$. (Table 2)

Table (2): Circumstances of poisoning in all studied patients

\begin{tabular}{|c|c|c|c|}
\hline & N. & Percentage \% \\
\hline \multirow{2}{*}{$\begin{array}{l}\text { Manner of } \\
\text { poisoning }\end{array}$} & Accidental & 70 & 87.5 \\
\hline & Suicidal & 10 & 12.5 \\
\hline \multirow{2}{*}{$\begin{array}{l}\text { Route of } \\
\text { exposure }\end{array}$} & Combined & 60 & 75.0 \\
\hline & Ingestion & 20 & 25.0 \\
\hline \multirow[t]{5}{*}{$\begin{array}{c}\text { Type of } \\
\text { pesticides }\end{array}$} & $\begin{array}{c}\text { Anticholinesterase } \\
\text { insecticides }\end{array}$ & 46 & 57.5 \\
\hline & Phosphides & 18 & 22.5 \\
\hline & Pyrethroid & 2 & 2.5 \\
\hline & Organochlorine & 2 & 2.5 \\
\hline & Unknown & 12 & 15.0 \\
\hline
\end{tabular}

$\mathbf{N}$ : Number
Patients with normal level of consciousness outnumbered those with disturbed level of consciousness whose GCS was $\leq 12$. The majority of patients suffered from vomiting, abdominal colic, diarrhea, crepitations, miosis, and hypotonia.

As obvious in Table 4, The median hemoglobin levels and the mean red blood cell counts were comparable between all groups and did not show statistical significant differences between the different studied groups ( $\mathrm{P}$ value 0.792 and 0.119 , respectively).

Table (3): Clinical manifestations of the poisoned patients

\begin{tabular}{|c|c|c|c|}
\hline \multicolumn{2}{|c|}{ Clinical findings } & N=80 & $\begin{array}{c}\text { Percentage } \\
\text { \% }\end{array}$ \\
\hline Consciousness & GCS $\geq 13$ & 48 & 60.0 \\
\cline { 2 - 4 } & GCS $\leq 12$ & 32 & 40.0 \\
\hline \multirow{2}{*}{ Miosis } & Yes & 60 & 75.0 \\
\cline { 2 - 4 } & No & 20 & 25.0 \\
\hline Fasciculations & Yes & 34 & 42.5 \\
\cline { 2 - 4 } & No & 46 & 57.5 \\
\hline Hypotonia & Yes & 42 & 52.5 \\
\cline { 2 - 4 } & No & 38 & 47.5 \\
\hline Crepitations & Yes & 42 & 52.5 \\
\cline { 2 - 4 } & No & 38 & 47.5 \\
\hline \multirow{3}{*}{ Wheeze } & Yes & 36 & 45.0 \\
\cline { 2 - 4 } & No & 44 & 55.0 \\
\hline Vomiting & Yes & 64 & 80.0 \\
\cline { 2 - 4 } & No & 16 & 20.0 \\
\hline Abdominal & Yes & 68 & 85.0 \\
\cline { 2 - 4 } colic & No & 12 & 15.0 \\
\hline Diarrhea & Yes & 59 & 73.6 \\
\cline { 2 - 4 } & No & 21 & 26.4 \\
\hline
\end{tabular}

GCS: Glasgow Coma Scale, N: Number

Biomarkers of inflammation studied from CBC were total white blood cells (WBCs), neutrophils, lymphocytes, and platelets. Patients of group (3) had significant higher total WBCs, neutrophil and platelet count compared with the other groups $(\mathrm{P}<0.001)$. In contrast, patients of group (3) exhibited statistically significant lowest 
lymphocyte count in comparison with groups $1 \& 2(\mathrm{P}<0.001)$. Regarding the hematological parameters, group (3) had significantly higher RDW\%, NLR and PLR than groups $1 \& 2$ (P <0.001).

Table 4

From the ROC curves, patients were considered of bad prognosis when

Table (4): Statistical analysis (Posthoc test) of the hematological parameters in the different studied groups

\begin{tabular}{|c|c|c|c|c|c|c|}
\hline \multirow{2}{*}{\multicolumn{2}{|c|}{ Hematological elements }} & \multicolumn{3}{|c|}{ Groups } & \multicolumn{2}{|c|}{$\begin{array}{l}\text { Kruskal-Wallis } \\
\text { \& ANOVA tests }\end{array}$} \\
\hline & & $\begin{array}{c}\text { Group (1) } \\
\mathbf{N}=22 \\
(27.5 \%)\end{array}$ & $\begin{array}{c}\text { Group (2) } \\
\mathrm{N}=\mathbf{2 6} \\
(32.5 \%)\end{array}$ & $\begin{array}{c}\text { Group (3) } \\
\mathrm{N}=32 \\
(\mathbf{4 0 . 0 \% )}\end{array}$ & $\begin{array}{c}\text { Test } \\
\text { statistic }\end{array}$ & P value \\
\hline Hb (gm) & Median (IQR) & $12.0(11.4-13.1)$ & 12.4(11.7-13.1) & $12.3(11.3-13.8)$ & 0.467 & 0.792 \\
\hline RBCs $\times 10^{6}$ & Mean \pm SD & $4.66 \pm 0.31$ & $4.49 \pm 0.38$ & $4.87 \pm 0.56$ & 2.320 & 0.119 \\
\hline $\mathrm{WBCs}\left(\times 10^{3}\right)^{\#}$ & Mean \pm SD & $8.21 \pm 1.05$ & $9.55 \pm 1.42$ & $13.32 \pm 1.05$ & 70.23 & $<0.001 *$ \\
\hline $\begin{array}{l}\text { Neutrophils } \\
\left(\times 10^{3}\right)^{\$}\end{array}$ & Median (IQR) & $3.71(2.87-3.97)$ & $3.68(3.37-3.98)$ & $6.65(5.93-8.15)$ & 28.15 & $<0.001 *$ \\
\hline $\begin{array}{l}\text { Lymphocytes } \\
\left(\times 10^{3}\right)^{\#}\end{array}$ & Median (IQR) & $1.82(1.32-2.02)$ & $1.02(0.95-1.05)$ & $0.8(0.79-0.87)$ & 30.28 & $<0.001 *$ \\
\hline Platelets $\left(\times 10^{3}\right)^{\$}$ & Median (IQR) & $190(180-199)$ & $191(184-205)$ & $\begin{array}{c}288(255.45- \\
326.4)\end{array}$ & 26.63 & $<.001^{*}$ \\
\hline RDW\% \% & Mean \pm SD & $13.17 \pm .48$ & $13.47 \pm 1.21$ & $15.49 \pm .91$ & 36.32 & $<0.001 *$ \\
\hline NLR $^{\$}$ & Median (IQR) & $2.02(1.87-2.33)$ & $3.87(3.30-4.14)$ & $8.63(7.00-10.33)$ & 33.068 & $<0.001 *$ \\
\hline PLR $^{\#}$ & Mean \pm SD & $116.36 \pm 25.60$ & $200.63 \pm 29.0$ & $362.51 \pm 59.45$ & 109.61 & $<0.001 *$ \\
\hline
\end{tabular}

RDW: Red cell Distribution Width, NLR: Neutrophil Lymphocyte ratio, PLR: Platelet Lymphocyte Ratio, gm: gram, SD: Standard Deviation, IQR: interquartile range, $\mathbf{P}^{*}$ significant if $\leq 0.05$, N: Number

Table (5): The best cut off, sensitivity and specificity for prediction of the outcome of pesticide intoxication by Red cell Distribution Width (RDW \%), Neutrophil Lymphocyte ratio (NLR), and Platelet Lymphocyte Ratio (PLR)

\begin{tabular}{|c|c|c|c|c|c|c|}
\hline $\begin{array}{l}\text { Hematological } \\
\text { parameters }\end{array}$ & Cut off & Sensitivity & Specificity & Accuracy & AUC & P value \\
\hline RDW\% & $\geq 14.30$ & $93.8 \%$ & $83.3 \%$ & $90 \%$ & 0.96 & $<0.001^{*}$ \\
\hline NLR & $\geq 6.49$ & $87.5 \%$ & $95.8 \%$ & $92.5 \%$ & 0.97 & $<0.001^{*}$ \\
\hline PLR & $\geq 292.87$ & $87.5 \%$ & $91.7 \%$ & $90 \%$ & 0.98 & $<0.001^{*}$ \\
\hline
\end{tabular}

RDW: Red cell Distribution Width, NLR: Neutrophil Lymphocyte Ratio, PLR: Platelet Lymphocyte Ratio, AUC: Area Under the Curve, $\mathrm{P}^{*}$ significant if $\leq 0.05$

Table 6 presented that there was no significant association between the type of pesticides and the evaluated hematological ratios (P value $>0.05$ ). In the current study, there was significant strong negative correlation between plasma pseudocholinesterase enzyme activity and RDW\%, NLR and PLR (P 
value $<0.001)$ as it is obvious in Figures

\section{2,3 and 4.}

Table (6): Statistical analysis for detection the association between the types of pesticides and Red cell Distribution Width, Neutrophil Lymphocyte ratio, and Platelet Lymphocyte Ratio

\begin{tabular}{|c|c|c|c|c|c|c|}
\hline \multirow{2}{*}{ Hematological parameters } & \multicolumn{3}{|c|}{ Types of pesticides } & \multicolumn{2}{c|}{$\begin{array}{c}\text { Kruskal-Wallis \& } \\
\text { ANOVA tests }\end{array}$} \\
\cline { 2 - 7 } & Anticholinesterases & Phosphides & Unknown & Test statistic & P \\
\hline \multirow{2}{*}{ RDW } & Mean \pm & $14.24 \pm$ & $14.16 \pm$ & $13.40 \pm$ & 0.937 & 0.401 \\
& SD & 1.43 & 1.13 & 1.36 & & \\
\hline NLR & Median & 3.90 & 6.10 & 2.98 & 2.06 & 0.367 \\
& (IQR) & $(2.17-7.11)$ & $(3.30-8.63)$ & $(2.24-4.43)$ & & \\
\hline PLR & Median & 195.79 & 324.3 & 233.33 & 1.85 & 0.454 \\
& (IQR) & $(114.3-324.3)$ & $(173.91-369)$ & $(180-309.5)$ & & \\
\hline
\end{tabular}

RDW: Red cell Distribution Width, NLR: Neutrophil Lymphocyte ratio, PLR: Platelet Lymphocyte Ratio, SD: Standard Deviation, IQR: Interquartile Range, P: significant if $<0.05$

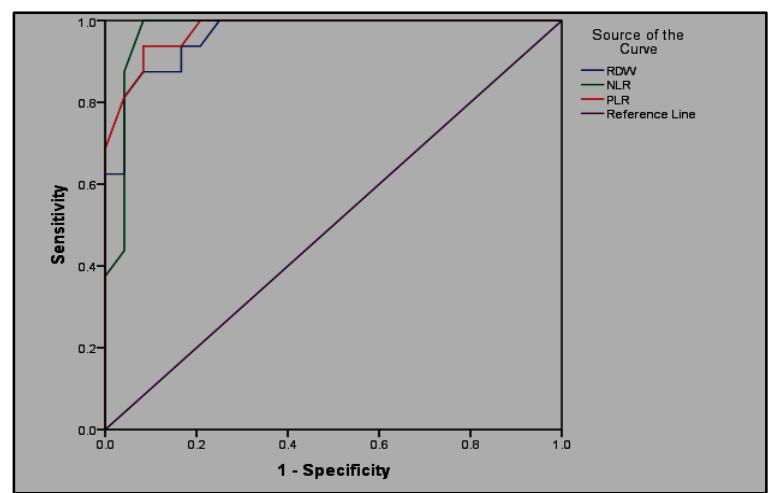

Fig. 1: Receiver Operating Characteristic (ROC) curves of Red cell Distribution Width (RDW\%), Neutrophil Lymphocyte ratio (NLR), and Platelet Lymphocyte Ratio (PLR) for prediction of the prognosis of the pesticide poisoned patients.

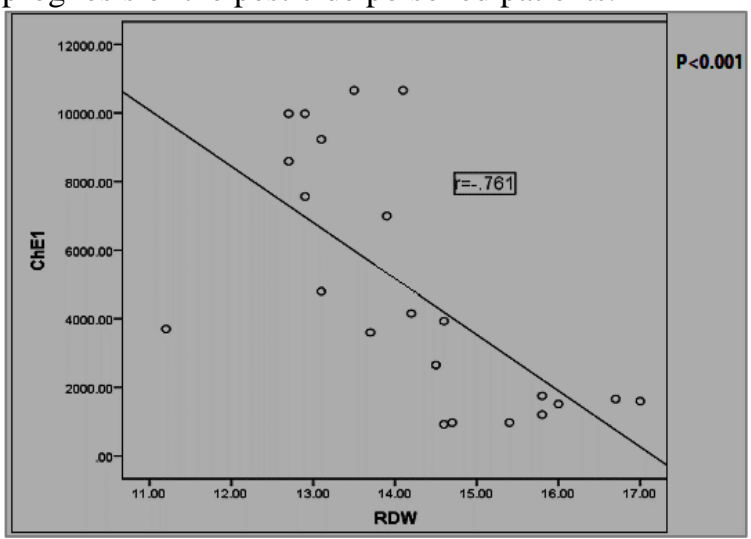

Fig. 2: Spearman rank Correlation between Red cell Distribution Width (RDW\%) and plasma cholinesterase (ChE1) activity. r: Correlation Coeffecient, $\mathrm{P}^{*}$ : significant if $\leq 0.05$

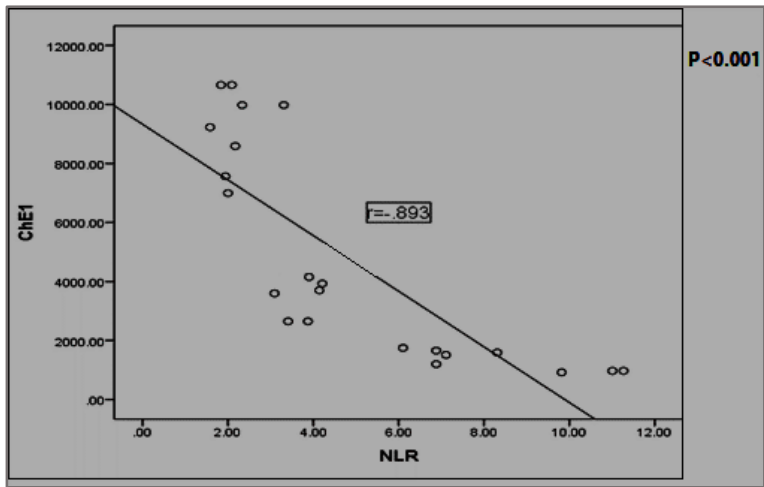

Fig. 3: Spearman rank Correlation between Neutrophil Lymphocyte ratio (NLR) and plasma cholinesterase (ChE1) activity. r: Correlation Coeffecient, $\mathrm{P}^{*}$ : significant if $\leq 0.05$

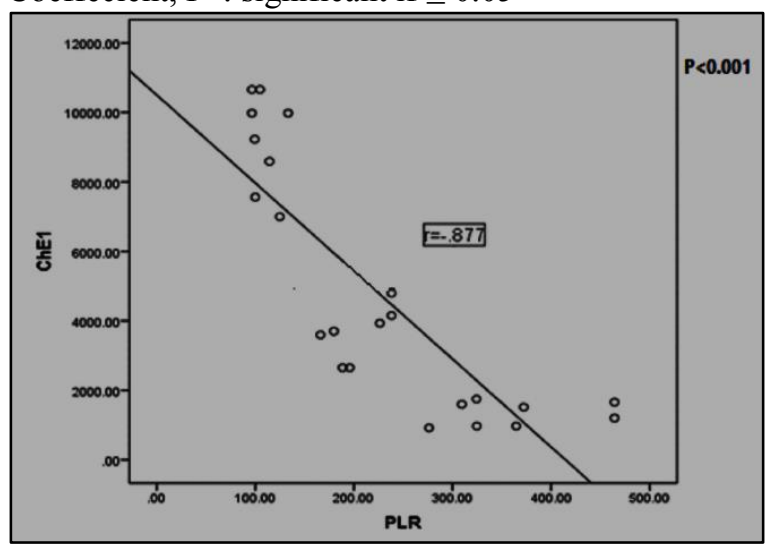

Fig. 4: Spearman rank correlation between Platelet Lymphocyte Ratio (PLR) and plasma cholinesterase (ChE1) activity. r: Correlation Coeffecient, $\mathrm{P}^{*}$ : $\begin{array}{lll}\text { significant } & \text { if } & 0.0\end{array}$ 


\section{DISCUSSION}

In Egypt, Pesticides (mainly anticholinesterase insecticides) intoxication is the most frequent cause of morbidity and mortality among the nonpharmaceutical agents poisoning (Azab et al., 2016). Many studies revealed higher rates of pesticide poisoning in developing countries, especially in rural areas where pesticides are poorly regulated and easily available (Eddleston et al., 2002 and Andiran \& Sarıkayalar, 2004). The socioeconomic status, cultural practices, local industrial and agricultural activities reflected on the variation between countries and populations (Peden et al., 2008).

In the current study, the mean duration of hospital stay was $5.3 \pm 3.2$ days, which was consistent with Dündar et al. (2014) who found that the mean duration of hospitalization was $(4.25 \pm 4.63)$ days.

The mean hemoglobin level exhibited no statistically significant differences between the studied groups. In agreement with these findings, Al-Sarar et al. (2009) and Dündar et al. (2015) who reported that $\mathrm{Hb}, \mathrm{MCV}, \mathrm{MCH}$, and MCHC remained unchanged with organophosphates poisoning. Similarly, Dündar et al. (2014) and Kang et al. (2014) stated that there was no statistical significant difference between survivors and non-survivors in terms of $\mathrm{Hb}$ and hematocrit value following pesticides and organophosphates poisoning ( $\mathrm{P}$ $=0.117$ and 0.569), respectively. This was explained on the basis that $\mathrm{CBC}$ was done within the first 24 hours where the antioxidant capacity of erythrocytes was not worn out (Dündar et al., 2015). Statistical studying of CBC indices revealed statistically significant leukocytosis, neutrophilia, lymphopenia, and thrombocytosis in death group (3) if compared with patients of groups $1 \& 2$. These results were similar to the study of Tang et al. (2018) who found significant difference between the healthy, the moderate and the severe groups of organophosphates poisoning in terms of WBCs, neutrophil, platelet and lymphocyte. In addition, they detected significant difference between the survival, the death, and the healthy groups of paraquat poisoning regarding the same indices.

Moreover, these findings were in partial agreement with Dündar et al. (2014) and Zhou et al. (2016) as they did not detect statistically significant differences between the studied groups of pesticide poisoning in terms of lymphopenia and thrombocytosis. Ambali et al. (2010) have reported thrombocytosis in subacute and chronic pesticide poisoning in rats while Ambali et al. (2011) have reported thrombocytopenia. Thrombocytopenia is commonly noticed in non-poisoning clinical settings (de Jager et al., 2010 and Wright et al., 2010)

The above-mentioned results could be elucidated that acute pesticide poisoning results in an extensive body inflammatory reaction due to oxidative stress as they induce excessive production of free radicals or impair the antioxidant mechanisms of the body (Abdollahi et al., 2004; Hernández et al., 2013). Free radicals can elicit lipid peroxidation of the cellular membrane with subsequent cellular damage (Xu et al., 2014) and produce chemokine production (Michalec et al., 2002). As a result, leukocytosis, neutrophilia, and 
lymphopenia could be detected in the acute clinical course when the oxidative stress is increased (de Jager et al., 2010 and Wright et al., 2010).

The results of the current study showed that RDW\%, NLR and PLR were statistically elevated in death group. These results were comparable with Dündar et al. (2014), Kang et al. (2014) and Dündar et al. (2015), studies who reported significant difference between the different studied groups of pesticides and organophosphates poisoning.

The explanation of these findings was attributed to the resulted status of acute inflammation and increased oxidative stress following pesticides poisoning which escalates anisocytosis thus increases RDW. This may be mediated by the deformation of erythrocyte membranes, erythropoiesis disruption and destruction and shortening $\mathrm{RBCs}$ half-lives (Şenol et al., 2013). Furthermore, the released inflammatory cytokines reduce RBCs maturation in bone marrow, consequently, immature RBCs escape into circulation, eventually elevating the RDW (Pierce and Larson, 2005).

In this study, the ROC curve analysis displayed the significant association between the RDW\%, NLR \& PLR and prognosis of acute pesticides poisoning. The most sensitive parameter was RDW\% (93.8\%) with cut off value 14.30, while the most specific parameter was NLR $(95.8 \%)$ with cut off value of 6.49. Dündar et al. (2015) found that the cut off value and sensitivity of RDW\% In anticholinesterases poisoned patients, the plasma pseudocholinesterase activity was significantly and negatively correlated with RDW\%, NLR and PLR. for predicting the prognosis in organophosphates poisoning were $>14.5 \%$ and $73 \%$, respectively. Additionally, Dündar et al. (2014) reported the cut off value and specificity of NLR for predicting mortality in acute pesticide poisoning were 7.1 and $66 \%$, respectively. Furthermore, they found that the cut off value and specificity of PLR for predicting the mechanical ventilation requirements were 217.5 and $80 \%$, respectively. Therefore, RDW\%, NLR, and PLR may be useful and simpler parameters in assessing the prognosis of pesticide poisoning.

By further statistical analysis, there was not significant association between the type of pesticide involved in the toxicity and the assessed hematological parameters (RDW, NLR and PLR). In disagreement with these results was Mecdad et al. (2011) study who revealed significant elevation of tumor necrosis factor level (immunological biomarkers of inflammation) in insecticides-exposed workers versus fungicides exposed workers and control. Additionally, Tang et al. (2018) stated that when the severe organophosphates poisoned patients were compared with the death group of paraquat, the statistical difference indexes included WBCs, neutrophil, eosinophil, basophil, monocyte, lymphocyte, and platelet. Hence, the NLR and PLR were significantly different between these groups but the RDW\% was not significantly different.

Plasma cholinesterase is an enzyme that hydrolyzes acetylcholine. It has an essential role during inflammatory reaction and represents an accurate index 
of cholinergic activity (Zivkovic et al., 2018). It is considered as negative inflammatory reactants, whose serum levels are inversely associated with the increasing degree of inflammation (Zivkovic et al., 2016). These findings confirmed that these hematological parameters could assess the severity and prognosis of anticholinesterase insecticides poisoning when there was no laboratory facility to measure the plasma level of pseudocholinesterase activity such as in health institutions of developing countries.

\section{CONCLUSION}

Measurement of Red cell distribution width, Neutrophil lymphocyte ratio, and platelet lymphocyte ratio within 24 hours of pesticide exposure and prior the administration of any medications are useful, valuable, inexpensive and easily accessible parameters in estimating prognosis and the follow-up of patients with acute pesticide poisoning in contrast to other novel prognostic markers.

The sample of this study was small, thus, it may decrease the statistical power of the study. Thus, we recommend that further controlled studies should be conducted on large scale of patients from multi-centers to be able to analyze the pesticide subgroups and to validate these parameters as prognostic markers.

\section{REFERENCES}

Abdollahi, M.; Ranjbar, A.; Shadnia, S.; Nikfar, S. and Rezaiee, A. (2004): Pesticides and oxidative stress: a review. Med Sci Monit, 10(6):144-147.

Alan a, S.; Tuna, S. and Turkoglu, E. (2015): The relation of neutrophilto-lymphocyte ratio, platelet-tolymphocyte ratio, and mean platelet volume with the presence and severity of Behcet's syndrome. Kaohsiung Journal of Medical Sciences, 31: 626-631.

Al-Sarar, A.S.; Abo Bakr, Y.; AlErimah, G.S.; Hussein, H.I. and Bayoumi, A.E. (2009): Hematological and biochemical alterations in occupationally pesticides-exposed workers of Riyadh Municipality, Kingdom of Saudi Arabia. Res J Environ Toxicol, 3: 179-185.

Ambali, S.F.; Abubakar, A.T.; Shittu, M.; Yaqub, L.S.; Anafi, S.B. and Abdullahi, A. (2010): Chlorpyrifosinduced alteration of hematological parameters in Wistar rats: ameliorative effect of zinc. Res J Environ Toxicol, 4:55-66.

Ambali, S.F.; Ayo, J.O.; Esievo, K.A. and Ojo, S.A. (2011): Hemotoxicity induced by chronic chlorpyrifos exposure in Wistar rats: mitigating effect of vitamin C. Vet Med Int, 2011:945439.

Andıran, N. and Sarıkayalar, F. (2004): Pattern of acute poisonings in childhood in Ankara: what has changed in twenty years? Turk J Pediatr, 46(2):147-152.

Azab, S.M.S.; Hirshon J.M.; Hayes, B.D.; El-Setouhye, M.; Smith, G.S.; Sakr, ML. et al., (2016): Epidemiology of acute poisoning in children presenting to the poisoning treatment center at Ain Shams University in Cairo, Egypt, 20092013. Clin Toxicol (Phila), 54(1): 20-26.

Balta, S.; Demirkol, S.; Cakar, M.; Arslan, Z.; Unlu, M. and Celik, T. (2013): Other inflammatory markers 
should not be forgotten when assessing the neutrophil-tolymphocyte ratio. Clin Appl Thromb Hemost, 19(6): 693-694.

Bertolote, J.M.; Fleischmann, A.; Eddleston, M. and Gunnell, D. (2006): Deaths from pesticide poisoning: a global response. $\mathrm{Br} \mathrm{J}$ Psychiatry, 189: 201-203.

Cha, E. S.; Khang Y. and Lee, W.J. (2014): Mortality from and Incidence of Pesticide Poisoning in South Korea: Findings from National Death and Health Utilization Data between 2006 and 2010, PLOS ONE, 9 (4): e95299

Dabbah, S.; Hammerman, H.; Markiewicz, W. and Aronson, D. (2010): Relation between red cell distribution width and clinical outcomes after acute myocardial infarction. Am J Cardiol,105: 312317.

de Jager, C.P.; van Wijk, P.T.; Mathoera, R.B.; de JonghLeuvenink, J.; van der Poll, T. and Wever, P.C.

(2010):

Lymphocytopenia and neutrophillymphocyte count ratio predict bacteremia better than conventional infection markers in an emergency care unit. Critical care,14 (5):R192.

Dündar, Z.D.; Ergin, M.; Köylü, R.; Özer, R.; Cander, B. and Günaydin, Y.K. (2014): Neutrophillymphocyte ratio in patients with pesticide poisoning. The Journal of emergency medicine, 47:286-293.

Dündar, Z.D.; Köylü, R.; Ergin, M.; Günaydın, Y.K.; Özer, R. and Cander, B. (2105): Prognostic Value of Red Cell Distribution Width in Patients with
Organophosphate Poisoning. The Journal of Academic Emergency Medicine, 14:65-69.

Eddleston, M.; Karalliedde, L.; Buckley, N.; Fernando, R.; Hutchinson, G.; Isbister, G. et al., (2002): Pesticide poisoning in the developing world--a minimum pesticides list. Lancet, 360(9340):1163-1167.

Faiz, M.S.; Mughal, S. and Memon, A.Q. (2011): Acute and late complications of organophosphate poisoning. Journal of the College of Physicians and Surgeons Pakistan, 21(5):288-90.

Georgiadisa, N.; Tsarouhasb, K.; Tsitsimpikouc, C.; Vardavasd, A.; Ramin Rezaeee, R.; Germanakisf, I. et al., (2018): Pesticides and cardiotoxicity. Where do we stand? Toxicology and Applied Pharmacology, 353:1-14

Gunnell, D.; Eddleston, M.; Phillips, M.R. and Konradsen, F. (2007): The global distribution of fatal pesticide self-poisoning: systematic review. BMC Public Health, 7:357.

Hernández, A.F.; Lacasaña, M.; Gil, F.; Rodríguez-Barranco, M.; Pla, A. and López-Guarnido, O. (2013): Evaluation of pesticide-induced oxidative stress from a geneenvironment interaction perspective. Toxicology, 307:95-102.

Hu, Z.; Sun, Y.; Wang, Q. Han, Z.; Huang, Y.; Liu, X. et al., (2013): Red blood cell distribution width is a potential prognostic index for liver disease. Clin Chem Lab Med, 51:1403-1408.

Jo, Y.H.; Kim, K.; Lee, J.H.; Kang, C.; Kim, T.; Park, H.M. et al., 
(2013): Red cell distribution width is a prognostic factor in Group (3) sepsis and septic shock. American Journal of Emergency Medicine, 31: 545-548.

Kang, C.; Park, I.S.; Kim, D.H.; Kim, S.C.; Jeong, J.H.; Lee, S.H. et al., (2014): Red cell distribution width as a predictor of mortality in organophosphate insecticide poisoning. American Journal of Emergency Medicine, 32: 743-746

Kaya, A.; Kaya, Y.; Topçu, S.; Günaydin, $\quad$ Z.Y.; Kurt, M.; Tanboğa, I.H. et al., (2014): Neutrophil-to-lymphocyte ratio predicts contrast-induced nephropathy in patients undergoing primary percutaneous coronary intervention. Angiology, 65:51-56.

Kim, D.; Moon, J. and Chun, B. (2015): The Initial Hyperglycemia in Acute Type II Pyrethroid Poisoning. Journal of Korean Medical Science, 30(4):365-370.

Kim, J.; Kim, K.; Lee, J.H.; Jo, Y.H.; Rhee, J.E.; Kim, T.Y. et al., (2012): Red blood cell distribution width as an independent predictor of all-cause mortality in out of hospital cardiac arrest. Resuscitation, 83: 1248-52.

Knapp, H. (2017): Introductory Statistics Using SPSS. SAGE Publications, Inc.

Li, N.; Zhou, H. and Tang, Q. (2017): Red Blood Cell Distribution Width: A Novel Predictive Indicator for Cardiovascular and Cerebrovascular Diseases. Disease Markers. http://doi.org/10.1155/2017 /7089493
Mansour, S.A. (2004): Pesticide exposure-Egyptian scene. Toxicology, 198 (1-3):91-115

Mecdad, A.A.; Ahmed, M.H.; ElHalwagy, M.E.A. and Afify, M.M.M. (2011): A study on oxidative stress biomarkers and immunomodulatory effects of pesticides in pesticide-sprayers Egyptian Journal of Forensic Sciences, 1 (2): 93-98.

Mehrpour, O.; Jafarzadeh, M. and Abdolahi, M. (2012): A Systematic Review of Aluminium Phosphide Poisoning. Arhiv za higijenu rada $i$ toksikologiju, 63:61-73.

Michalec, L.; Choudhury, B.K.; Postlethwait, $\quad$ E.; Wild, J.S.; Alam, R.; Lett-Brown, M. et al., (2002): CCL7 and CXCL10 orchestrate oxidative stress-induced neutrophilic lung inflammation. Journal of immunology, 168: 846852.

Page, A.; Liu, S.; Gunnell, D.; AstellBurt, T.; Feng, X.; Wang, L. et al., (2017): Suicide by pesticide poisoning remains a priority for suicide prevention in China: Analysis of national mortality trends 2006-2013. Journal of Affective Disorders, 208: 418-423.

Peden, M.; Oyegbite, K.; OzanneSmith, J.; Hyder, A.A.; Branche, C.; Rahman, A.F. et al., (2008): World Report on Child Injury Prevention. World Health Organization; 2008. Available at: whqlibdoc.who.int/ publications/2008/9789241563574_e ng.pdf [July 8, 2015]

Pierce, C.N. and Larson, D.F. (2005): Inflammatory cytokine inhibition of 
erythropoiesis in patients implanted with a mechanical circulatory assist device. Perfusion, 20:83-90.

Şenol, K.; Saylam, B.; Kocaay, F. and Tez, M. (2013): Red cell distribution width as a predictor of mortality in acute pancreatitis. Am J Emerg Med, 31: 687-689.

Shehata, H.A; Ali, M.M.; Evans-Jones, J.C.; Upton, G.J. and Manyonda, I.T. (1998): Red cell distribution width (RDW) changes in pregnancy. International Journal of Gynaecology and Obstetrics, 62(1):43-6.

Tang, Y.; Hu, L.; Hong, G.; Zhong, D.; Song, J.; Zhaoand, G.; et al., (2018): Diagnostic value of complete blood count in paraquat and organophosphorous poisoning patients. Toxicology and Industrial Health, 34(7): 439-447

Wright, H.L.; Moots, R.J.; Bucknall, R.C. and Edwards, S.W. (2010): Neutrophil function in inflammation and inflammatory diseases. Rheumatology, 49:1618-1631.

Xu, L.; Xu, J. and Wang, Z. (2014): Molecular mechanisms of paraquatinduced acute lung injury: a current review. Drug and chemical toxicology, 37:130-134.

Zahorec, R. (2001): Ratio of neutrophil to lymphocyte counts-rapid and simple parameter of systemic inflammation and stress in critically ill. Bratisl Lek Listy, 102:5-14.

Zhou, D.C.; Zhang, H.; Luo, Z.M.; Zhu, Q.X. and Zhou, C.F. (2016): Prognostic value of hematological parameters in patients with paraquat poisoning. Scientific Reports, 6:36235, DOI: 10.1038/srep36235

Zivkovic, A.R.; Bender, J.; Brenner, T.; Hofer, S. and Schmidt, $K$. (2016): Reduced butyrylcholinesterase activity is an early indicator of trauma-induced acute systemic inflammatory response. Journal of Inflammation Research, 9:221-230.

Zivkovic, A.R.; Decker, S.O.; Zirnstein, A.C.; Sigl, A.; Schmidt, K.; Weigand, M. et al., (2018): A Sustained Reduction in Serum Cholinesterase Enzyme Activity Predicts Patient Outcome following Sepsis. Mediators of Inflammation, http://doi.org/10.1155/2018/1942193

Zorlu, A.; Bektasoglu, G.; Guven, F.M.; Dogan, O.T.; Gucuk, E.; Ege, M.R. et al., (2012): Usefulness of admission red cell distribution width as a predictor of early mortality in patients with acute pulmonary embolism. Am J Cardiol, 109: 128-134. 